\title{
NOTAS SOBRE ALGUMAS ESPÉCIES DE ABELHAS DA BAHIA, BRASIL (HYMENOPTERA, APOIDEA)
}

\author{
Jesus S. Moure ${ }^{2}$
}

\begin{abstract}
Notes on some bees from Bahia, Brasil. (Hymenoptera, Apoldea). Recently I have seen some bees from the State of Bahia, and because they are relatively rare the opportunity is taken to complete the short description of Oxaea nefa Friese, 1898, and register the new locality for this species and for Oxaea schwarzi Moure \& Seabra. 1962. Euglossa (Euglossella) cyanochlora, the largest known Euglossa Latreille, 1802 (length $19.5 \mathrm{~mm}$ ), a visitor of flowers of Solanaceae, is described as new. It is from Itamarajú, on the Southernmost part of Bahia. Euglossa (Euglossa) perfulgens Moure, 1967, helongs in the subgenus Euglossella Moure. 1967.

KEY WORDS. Apoidea, Oxaea, Euglossa. Cyphomandra, Solanum, taxonomy
\end{abstract}

Tive oportunidade de ver ultimamente na Coleção Campos Seabra, Museu Nacional do Rio de Janeiro (MNRJ), algumas espécies muito raras de Oxaéa Klug, 1807, e uma espécie nova de Euglossini. Resolví fazer algumas notas, já que muito pouco é o que se sabe sobre abelhas da Bahia e dar a conhecer a maior de todas as espécies conhecidas de Euglossa Latreille, 1802: Euglossa (Euglossella) cyanochlora, sp.n., coletada em flores de Solanum. Seu porte chega aos 19,5 mm. superando neste particular muitos representantes de Euplusia Moure, 1943.

\section{Oxaea rufa Friese, 1899}

Oxaea rufa Friese, 1899. Ann. k.k. naturhist. Hofmus., Wien. 14(3): 244, 6a.

Friese dá o seguinte diagnóstico: " 9 nigra, fuliginoso-hirta, capite sparsim punctato, nitido, clypeo evidenter elevato; abdomine rufo, segmento 6. nigro; pedibus fuliginosis, fusco-hirtis, scopa albida; alis fumatis, nervuris, tegulisque fulvis." Com o seguinte esclarecimento: "Oxaea rufa ähnelt der ferruginea, ist aber grösser und das Abdomen bis auf das sechste Segment roth."

Dá como localidade do tipo Pará, Brasil.

Trata-se de uma Oxaea típica, de cores contrastantes, de que dou apenas os extraordinários caracteres que a separam de todas espécies conhecidas do gênero.

Fêmea. Comprimento total aproximado $21,0 \mathrm{~mm}$, da asa anterior $16,0 \mathrm{~mm}$; largura da cabeça $7,0 \mathrm{~mm}$ e do segundo tergo cerca de $8,0 \mathrm{~mm}$.

1) Contribuição número 819 do Departamento de Zoologia. Universidade Federal do Paraná.

2) Departamento de Zoologia. Universidade Federal do Paraná. Caixa Postal 19020. 81531-990 Curitiha. Paraná, Brasil. Bolsista do CNPq 
Cabeça, tórax, pernas e propódeo pretos; abdômen de um vermelhoferrugíneo vivo, com algumas manchas escuras vagas nos esternos. As tégulas pretas; as asas moderadamente fuscas. Pilosidade na cabeça branca; no tórax, pernas e propódeo preta; no abdômen ferrugínea.

Pontuação densa na cabę̧a; fóveas faciais muito largas e rasas, o fundo mate micro-reticulado entre os pontos grandes esparsos e muito superficiais; muito mais esparsa ao longo do meio do clípeo, a superfície de um micro-reticulado muito fino um pouco irregular com grossas rugas vagas transversais, muito superficiais. Labro quase liso ao longo do meio, um pouco deprimido e fracamente alargado para o ápice, de bordo convexo aí mais liso, muito fino reticulado no restante. Os pontos de tamanho moderado no mesoscuto, os intervalos no terço distal posterior um pouco maiores que os pontos, mates e micro-reticulados; mais esparsa no escutelo e os intervalos mais brilhantes. Nos tergos toda a superfície sedosa e com brilho ceroso, os pontos muito esparsos no disco, mais densos para os lados, praticamente nulos nas largas depressões marginais; quinto tergo bastante mais forte e densamente pontuado. Os esternos com pontução fina. A placa pigidial grande, de contorno largamente parabólico, mais plana e elevada no disco, as bordas elevadas.

Fêmea. BRASIL, Bahia: Palmeiras (Palmeiras situa-se na região central da Bahia, ao noroeste do Parque Nacional da Chapada de Diamantina), V-1992, O. Roppa leg., depositada na Coleção Campos Seabra (Museu Nacional, Rio de Janeiro).

\section{Oxaea schwarzi Moure \& Seabra, 1962}

Oxaea schwarzi Moure \& Seabra. 1962. Journ. N. Y. Ent. Soc. 70: 235.

Brasil, Bahia: Maracás (970m), um macho e duas fềmeas, II-1963, F.M. Oliveira leg.; (Hotel da Divisa), um macho, XI-1973, C.A. Campos Seabra leg. . Este hotel, na BR-116, fica próximo à divisa com Minas Gerais. Na Coleção Campos Seabra, Museu Nacional, Rio de Janeiro.

Nas fêmeas, o quinto e sexto tergos com pilosidade largamente ferrugínea; nos machos, pálida.

A espécie foi descrita de Vitoria da Conquista, Bahia, intermédia entre as duas localidades agora citadas.

\section{Euglossa (Euglossella) cyanochlora, sp.n.}

Pertence ao grupo Euglossa mandibularis Friese, 1899, porém bastante maior. É a maior e mais volumosa de todas espécies conhecidas de Euglossa.

Fêmea. Comprimento total aproximado $19,5 \mathrm{~mm}$; da asa anterior, muito gasta nas bordas, cerca de $14,0 \mathrm{~mm}$; largura da cabeça $6,9 \mathrm{~mm}$ e do segundo tergo $8,0 \mathrm{~mm}$.

Cabeça e abdômen verdes, este com alguns reflexos dourados; tórax, pernas e propódeo de um azul violáceo. Labro e cantos inferiores do clípeo brancos; áreas 
translúcidas do labro relativamente pequenas, pardo-amarelado-pálidas; bordo apical estreitamente preto. Área malar preta; desta mesma cor o escapo, o pedicelo e os dois flagelômeros basais, os demais escuro-cinzentos anteriormente. Tégulas violáceas; asas levemente pardacentas. Pilosidade branca na face e nas genas; cerdas eretas pretas na fronte, vértice e no lado inferior das genas. Preta no tórax, pernas e propódeo. No abdômen as cerdas predominantemente pretas, finas, eretas nos três primeiros tergos, nos últimos com algumas cerdas esbranquiçadas; nos esternos distalmente longas e pretas. Pontuação densa na fronte; arcadas frontais lisas e áreas laterais aos ocelos largamente lisas; moderadamente densa no disco elevado do clípeo, mais esparsa nas paroculares inferiores; genas largamente lisas e com poucos pontos grossos junto às órbitas. Pontuação no disco do mesoscuto muito evidente de dois tamanhos; declives anteriores das gibas escutelares bastante lisos e brilhantes; densa nos meso- e metepisternos; bastante densa nos tergos, porém insignificante nas depressões marginais.

Complexo labiomaxilar chegando ao ápice do abdômen. Clípeo bastante elevado, os lados projetados para a frente, essa projeção, de perfil, comparável à largura dos olhos; carenas clipeais bem desenvolvidas, a mediana tendo sequência na supraclipeal e esta por um forte sulco desaparecendo na fronte; as laterais em ogiva, um pouco engrossadas sem se fechar superiormente. Área malar bem desenvolvida, um pouco mais longa que o diâmetro do terceiro flagelômero. Gibas escutelares muito pronunciadas, salientes, com grande tufo de pêlos pretos entre as mesmas, chegando ao bordo posterior.

Holótipo fêmea. Brasil, Bahia: Itamarajú, XII-1985, O. Roppa e J. Becker leg., depositada na Coleção Campos-Seabra, Museu Nacional, Rio de Janeiro. Visitando flores de "Fruta-do-lobo", Solanum sp.

Itamarajú fica no Sudeste Bahiano.

Apesar de numerosas coletas com cheiros artificiais nessa região e outras áreas próximas da Mata Atlântica, nunca foram coletados machos desse grupo de Euglossini, em que incluo também E. mandibularis Friese, 1899 e E. perfulgens Moure, 1967.

Euglossa mandibularis descrita por Friese de Blumenau (Santa Catarina, Brasil), é relativamente comum ao longo da Mata Atlântica, tendo sido muito coletada na Reserva Florestal a cuidados da Universidade Federal de Viçosa, MG. Frequenta flores de Cyphomandra Mart. ex Sendtm. e os machos são vistos nessas flores, porém nunca foram coletados em armadilhas com Cineol, Essência de Baunilha, ou Eugenol, colocadas nas proximidades. Esta talvez pudesse ser a explicação para a falta de certos machos nas coleções de Euglossini. Será necessário descobrir os cheiros das flores que os atraem e buscar similares de uso comercial.

Euglossa (Euglossa) perfulgens, da Mata Amazônica, é transferida para o subgênero Euglossella. Infelizmente não há referência às flores visitadas por esta espécie. As observações acima anotadas para as flores visitadas por $E$. mandibularis e E. cyanochlora me fazem pensar que estas possam ser de uma solanácea. 


\section{REFERÊNCIAS BIBLIOGRÁFICAS}

Friese, H. 1898. Monographie der Bienengattungen Megacilissa, Caupolicana und Oxaea. Ann. k.k. Naturhist. Hofmus., Wien, 14: 239-246.

Moure, J.S. 1967. Descrição de algumas espécies de Euglossinae. (Hym., Apoidea). Atas Simp. Biota Amazônica 5: 373-394.

1967. A check-list of the known Euglossine bees. (Hymenoptera, Apidae). Atas Simp. Biota Amazônica 5: 395-415.

Moure, J.S. \& C.A.C. Seabra. 1962. A new species of the genus Oxaea from Brazil (Hymenoptera: Apidae). Journ. N.Y. Ent. Soc. 70: 235-238.

Recebido em 06.V.1995; aceito em 12.IX.1995. 